九州大学学術情報リポジトリ

Kyushu University Institutional Repository

\title{
Measurement of Corn Production Efficiency in Different Counties of Hebei Province, China: A Model Based on Data Envelopment Analysis
}

Li, Dongpo

Laboratory of Agricultural and Farm Management, Division of International Agricultural Resource Economics and Business Administration, Department of Agricultural and Resource Economics, Graduate School of Bioresource and Bioenvironmental Sciences, Kyushu University; Institute of Rural Economics, Hebei Academy of Social Sciences

Nanseki, Teruaki

Faculty of Agriculture, Kyushu University

Takeuchi, Shigeyoshi

Faculty of Agriculture, Kyushu University

https://doi.org/10.5109/20339

出版情報: 九州大学大学院農学研究院紀要. 56 (2)，pp.409-415，2011-09. Faculty of Agriculture， Kyushu University

バージョン :

権利関係 : 


\title{
Measurement of Corn Production Efficiency in Different Counties of Hebei Province, China: A Model Based on Data Envelopment Analysis
}

\author{
Dongpo LI $^{1}$, Teruaki NANSEKI ${ }^{2 *}$ and Shigeyoshi TAKEUCHI ${ }^{2}$ \\ Laboratory of Agricultural and Farm Management, Division of International Agricultural \\ Resource Economics and Business Administration, \\ Department of Agricultural and Resource Economics, Faculty of Agriculture, \\ Kyushu University, Fukuoka 812-8581, Japan \\ (Received April 20, 2011 and accepted May 9, 2011)
}

\begin{abstract}
This study measures the production efficiency of corn in Hebei Province, China, basing on an inputoriented DEA model with the assumption of Variable Return to Scale (VRS). In this framework, 2 outputs and 6 inputs are included, based on the agricultural product survey conducted by Price and Cost Inspection Bureau of Hebei in 2008. The 44 counties sampled are treated as the Decision Making Units (DMUs). The result shows that, 22 counties are fully efficient and in the status of constant returns to scale; in 7 counties, production efficiency can only be improved through adjusting the farming scales; in the rest 15 counties, production efficiency can be improved through either reducing the inputs or compressing the farming scales. Slack analysis of outputs shows that comparing with technical improvement, much more margin lies in the socio-economic optimization. Meanwhile, the liquid inputs are similar in the efficient and inefficient counties, with less slack and radial movements; large differences, slack and radial movements exist amongst inputs connecting with the construction of agricultural infrastructure. Furthermore, production efficiency in corn and wheat are compared with the adoption of Crosstabs Analysis. Finally, policy implications are put forward, concerning the adjustment of farming scales, marketing facilitation thus improve the added value, construction of irrigating infrastructure and agricultural mechanization.
\end{abstract}

\section{INTRODUCTION}

Corn is one of the staple grain crops in China, growing from Heilongjiang in the northeast to Hainan in the south. Since the 1980s, with the economic development, although direct food demands have decreased, corn is increasingly needed in forage and food processing industries. As one of the 13 main grain-growing provinces in China, Hebei accounts for 8.69 percent of yields and 9.51 percent of sown areas in China's corn production of 2008 , ranked the $5^{\text {th }}$ and $4^{\text {th }}$ respectively. However, the average output was $338.41 \mathrm{~kg}$ per $m u$, less than the national mean of $370.38 \mathrm{~kg}$ per $m u$ and ranked $17^{\text {th }}$ amongst 31 provincial regions (China Statistical Yearbook, 2009). As Meng J., (2010) concluded, Hebei is advantageous in the scale of corn production, but disadvantageous in technical efficiency.

On the measurement of agricultural production efficiency, the literature can be divided into two categories. Meng L. et al. (2004), Hu et al. (2006) and Daniel et al. (2010), took different regions as the Decision Making Units (DMUs), while many other researchers set their DMUs to individual farms, including Zhuo et al. (2009), Bhima et al. (2010), etc. In the five-level hierarchy of Chinese administrative system, county is the lowest level

\footnotetext{
1 Laboratory of Agricultural and Farm Management, Division of International Agricultural Resource Economics and Business Administration, Department of Agricultural and Resource Economics, Graduate School of Bioresource and Bioenvironmental Sciences, Kyushu University; Institute of Rural Economics, Hebei Academy of Social Sciences, Shijiazhuang, Hebei Province, P. R. China

${ }^{2}$ Faculty of Agriculture, Kyushu University

* Corresponding author (E-mail: nanseki@agr.kyushu-u.ac.jp)
}

having complete government divisions and economic industries. Moreover, the government identifies the state of agricultural development and allocates funds in units of counties. Therefore, this study intends to measure corn production efficiency from the DMUs of different counties in Hebei Province, China.

Since the pioneering work of Farrell (1957), a considerable literature has devoted to the estimation of efficiency. Generally, they can be categorized into two approaches: the parametric functions symbolized by Stochastic Frontier Production (SFP) (Aigner et al., 1977), and the nonparametric Data Envelopment Analysis (DEA) (Charnes et al., 1978). Both methods estimate the efficiency frontier, which it is considered as the best performance observed among the firms, and calculate relative efficiency of the other firms. The main strengths of the SFP are that it deals with stochastic noise and permits statistical tests of hypotheses pertaining to production structure and degree of inefficiency. Meanwhile, the requirement of specified forms for the frontier production function is the main weakness of this approach. In contrast, using linear programming to construct a piece-wise frontier that envelops observations of all firms, DEA embraces the advantage that multiple inputs and outputs can be considered simultaneously, and they can even be quantified in different units of measurement. Moreover, this approach avoids the parametric specification of technology and the distributional assumption for the inefficiency terms, and it does not claim the weights on different inputs and outputs as well (Coelli et al., 2005).

In the field of agricultural production, many resources are used, including land, labor, fertilizer, water, etc, thus needs a multiple-input quantitative 
model to measure the efficiency. From the perspective of outputs, a variety of variables can be adopted to measure not only the physical yield but also the market value. All input and output variables are probably in different units, without any parameters can be assumed accurately. Therefore, we will measure the production efficiency of corn using an input-oriented DEA model with the assumption of $\mathrm{VRS}^{1}$. As in many instances, the choice of orientation has only a minor influence upon the scores obtained. Essentially, one should select the orientation according to which quantities (inputs or outputs) the managers have most control over (Coelli et al., 2005). In agricultural production, what most of the famers can really control would be the quantity of inputs, rather than the outputs. Meanwhile, natural and marketing risks, government regulations, constraints on finance, etc., may cause a farm cannot operate at optimal scale.

In this study, we intend to fulfill the following targets: 1) formulating a DEA model appropriate to analyze corn production efficiency taking Chinese counties as the DMUs, 2) revealing the overall attributes of corn production efficiency, 3) finding out the theoretical margin for the increasing of each output and saving of inputs in the sampled counties of Hebei Province, 4) and putting forward policy recommendations.

\section{VARIABLES AND DATA SPECIFICATION}

\section{Defining the variables}

Considering the realities of agricultural production in the sampled counties, combining with the mechanism of DEA and referring to the previous researches, the study intends to specify a model consisting of 2 outputs and 6 inputs, to measure the corn production efficiency (Table 1).
Output variables For most of the farmers, agricultural products including corn, wheat, etc, are not only indispensible food stuff, but also important sources of income. Observing from a macroscopic view, efficient production of agricultural products is vital for food selfsufficient and poses a foundation for the national economy as well. For these reasons, two variables are included as outputs: Yields of main product refers to the net weight of raw corn in standard moisture content ${ }^{2}$. This variable implicates the physical productivity, hence the capability of fulfilling the corn demand and guarantee food safety in each county. Net profit is the balance of the gross profit minus costs of all the inputs revealing the profitability of corn production, determined by a variety of technical, marketing and political institutions. Therefore, the greatest difference between the two output variables is that the former is a technical indicator, while the latter is a socio-economic one.

Input variables (1) Farming time is the standard days of laboring needed by corn production. To calculate this variable, the farming time of both family members and hired labors should be standardized referring to a moderate labor $^{3}$, and then divided by 8 hours. (2) Land rent is monetary value of land inputted as a productive element, including real rent of land circulated from individuals or the collectives, and theoretical rent of farmland allocated by the Household Contract Responsibility System. (3) Physical amount of seeds used in corn production, including the bought, self-produced and donated for free, form the variable of Seeds here. (4) Similarly, Fertilizer is the amount of fertilizer used in corn production, which has been standardized according to the contents of active principles ${ }^{4}$. (5) Machine rent is the expenditure for the mechanical operations including plough, sowing, harvest, threshing and transportation. (6) Irrigation cost includes the

Table 1. Variables and the summary statistics of corn production efficiency

\begin{tabular}{|c|c|c|c|c|c|c|c|c|}
\hline Variable & & Description of the variable & Unit & $\operatorname{Max}$ & Min & Mean & Std. D & C. V. \\
\hline \multirow{2}{*}{ Output } & $y_{1}$ & Yields of main Product & $k g / m u^{*}$ & 546.30 & 349.40 & 468.73 & 55.71 & 0.12 \\
\hline & $y_{2}$ & Net profit & yuan/mu & 412.15 & 16.76 & 179.95 & 89.44 & 0.50 \\
\hline \multirow{6}{*}{ Input } & $x_{1}$ & Farming time & $d a y / m u$ & 10.11 & 3.50 & 6.48 & 1.49 & 0.23 \\
\hline & $x_{2}$ & Land rent & yuan/mu & 141.67 & 46.67 & 100.70 & 22.08 & 0.22 \\
\hline & $x_{3}$ & Seeds & $\mathrm{kg} / \mathrm{mu}$ & 3.61 & 2.34 & 2.82 & 0.26 & 0.09 \\
\hline & $x_{4}$ & Fertilizer & $\mathrm{kg} / \mathrm{mu}$ & 31.30 & 9.74 & 17.42 & 5.04 & 0.29 \\
\hline & $x_{5}$ & Machine rent & yuan/mu & 85.56 & 17.44 & 54.61 & 18.88 & 0.35 \\
\hline & $x_{6}$ & Irrigation cost & yuan $/ m u$ & 55.89 & 0.00 & 18.79 & 13.10 & 0.70 \\
\hline
\end{tabular}

Note: *as a main unit of land measurement in China, $1 \mathrm{mu}=666.67 \mathrm{~m}^{2}$.

Data source: agricultural product survey 2008, Price and Cost Inspection Bureau of Hebei

1 There are two orientations in DEA model, the input-oriented model seeks to reduce in inputs, with outputs hold constant, while the output-oriented model aims to increase outputs, with inputs keep fixed. As to the assumption of return to scale, Constant Return to Scale (CRS) is appropriate when all firms are operating at an optimal scale, while Variable Return to Scale (VRS) without this limitation.

2 Standard moisture content is the percentage of water and varies in different regions. In most of the cases, it is around $12-13$ percent in Hebei province.

${ }^{3}$ Moderate labors including: 1) 18-50 year old male and 18-45 year old female, able to adapt moderate labor intensity. 2) labors out of the age interval stipulated above, but can undertake equivalent labor intensity. and 3) the employed labors.

${ }_{4}^{4}$ For example, $50 \mathrm{~kg}$ of diammonium phosphate containing 18 percent of nitrogen and 46 percent of phosphorus pentoxide will be standardized as $32 \mathrm{~kg}(50 \mathrm{~kg} \times 18 \%+50 \mathrm{~kg} \times 46 \%)$. The chelate fertilizers and bacterial manure need not be standardized. 
expenditure for the rent of irrigating equipments, and the costs occurred in irrigating.

\section{Sample and data}

The data of inputs and outputs used in this study is gathered from the agricultural product survey, conducted by Price and Cost Inspection Bureau of Hebei in 2008. As a branch of the national survey of China, the survey covered the staple agricultural products, including wheat, rice, corn, cotton, pork, egg, and the characteristic agricultural products like pear, date, apple, etc. The survey was conducted throughout almost 1000 farms, distributing in 76 counties of all the 11 prefectures in Hebei. All the sampled farms are paid for keeping regular records of the inputs and outputs in the farming of each product. In terms of corn production, 44 counties of all the 11 prefectures of Hebei Province were sampled and the summary statistics are listed in Table 1.

\section{EFFICIENCY ANALYSIS WITH DEA}

\section{The basic model}

Being models to describe production efficiency, DEA includes a series of mathematical procedures using linear programming to construct a non-parametric frontier over the data, and efficiency measures are then calculated relative to this surface (Coelli et al., 2005). Charnes et al. (1978) proposed an input-orientated model with the assumption of CRS, which is being widely applied thereafter. However, the CRS is appropriate when of all firm are operating at an optimal scale, which could be easily broken due to imperfect competition, government regulations, constraint on finance, etc (Coelli et al., 2005). Banker et al. (1984) adopted the adjusted CRS model to account for the situations of VRS, by adding the constraint of I1' $\lambda=1$ to provide:

$$
\begin{aligned}
& \underset{\theta_{i} \lambda_{i}}{\operatorname{Min}} \theta_{i} \\
& \text { st. }-y_{i}+Y \lambda_{i} \geq 0, \\
& \quad \theta_{i} x_{i}-X \lambda_{i} \geq 0, \quad(i=1,2, \ldots, n) \\
& \quad I^{\prime} \lambda_{i}=1 \\
& \quad \lambda_{i} \geq 0,0 \leq \theta_{i} \leq 1
\end{aligned}
$$

where $Y$ and $X$ are the output and input matrices, while $y_{i}$ and $x_{i}$ are the outputs and inputs for the $i$-th firm, respectively. $\lambda_{i}$ is an $n \times 1$ vector for each firm, and serves as a weight system to each firms and thus form a optimal combination of inputs and outputs (the fron- tier). Meanwhile, $\theta_{i}$ is a scalar for each firm, indicating the extent of $x_{i}$ been used to catch up the optimal combination of inputs, and a value of one indicates a point on the frontier, and hence a technically efficient DMU (Farrell, 1957). Moreover, I1 is an $n \times 1$ vector of ones, ensuring that sum of all the weights assigned to the benchmarking firms equal to 1, thus the fabricated benchmarks (the optimal combination of inputs and outputs) are similar in scale with the $i$-th firm (Coelli et al., 2005). The DEA model of equation (1) seeks to reduce the inputs as much as possible, relative to the empirically constructed identical and optimal combination of inputs and outputs (Maria P. et al., 2010).

Scale efficiency measures can be obtained for each firm by conducting both CRS and VRS DEA, and then decomposing the TE scores obtained from the CRS DEA (the total efficiency) into two components: one due to the scale inefficiency and one due to pure technical inefficiency (i.e. VRS TE). If there is a difference in the CRS and VRS, then it indicates the existence of scale inefficiency for a particular firm (Coelli et al., 2005).

\section{Total, technical and scale efficiency}

The efficiency summary provided by DEAP 2.1 shows that, amongst the 44 counties, 22 counties are scored 1 in Total, Technical and Scale efficiency, thus being deemed as in the status of full efficiency and can be stand for benchmarks for the other inefficient counties. For convenience of analysis, the 22 counties are defined as Type I in this study. Furthermore, within the rest 22 counties with Total efficiency less than 1, 7 counties, referred as Type II, bear Technical efficiency equals to 1 . It indicates that in these counties, adjustment of any input will not change the output efficiency, thus adjusting the managerial scales is the only solution to improve production efficiency. Meanwhile, there are still 15 counties, referred as Type III, have technical efficiencies scoring less than 1 (Table 2). It means that in these counties, with given managerial scale, production efficiency can still be improved through reducing some of the inputs. In fact, it is an important objective and function of DEA model to identify and calculate quantity of inputs reduction for this kind of firms, as to be shown for the 15 Type III counties later in this study.

As the theoretical analysis above, all the 22 counties in Type I are in the status of constant returns to scale,

\begin{tabular}{|c|c|c|c|c|c|c|c|}
\hline \multirow{2}{*}{ Type } & \multirow{2}{*}{$\begin{array}{c}\text { Number of } \\
\text { counties }\end{array}$} & \multicolumn{3}{|c|}{ Means } & \multicolumn{3}{|c|}{ Number of counties with } \\
\hline & & Total efficiency & Technical efficiency & Scale efficiency & crs & irs & $d r s$ \\
\hline I & 22 & 1.000 & 1.000 & 1.000 & 22 & 0 & 0 \\
\hline II & 7 & 0.942 & 1.000 & 0.942 & 0 & 5 & 2 \\
\hline III & 15 & 0.846 & 0.938 & 0.903 & 0 & 15 & 0 \\
\hline Total & 44 & 0.938 & 0.979 & 0.959 & 22 & 20 & 2 \\
\hline
\end{tabular}
while in Type II, 5 counties are in the status of increasing returns to scale and 2 counties are in the status of decreasing returns to scale. In Type III, all the 15 coun-

Table 2. Summary of corn production efficiency

Note: $c r s=$ constant returns to scale; $i r s=$ increasing returns to scale; $d r s=$ decreasing returns to scale 
ties are being increasing returns to scale. Therefore, efficiencies of corn production can be improved by enlarging the managerial scales in 20 counties, while in 2 counties by contraction.

\section{Slack and radial analysis}

Slack of output shows the margin that a firm can increase the output through the adjustment proposed by DEA. In this study, only in the Type III counties, outputs can be increased through the adjustment according to the results of DEA. The slacks summarized in Table 3 show that in this group, yields of main product per mu can be increased by 1.93 percent, with the average slack of $26.59 \mathrm{~kg}$. Meanwhile, the net profit per mu can be increased by 83.80 yuan, and the slack adjustments account for 15.88 percent in the origin values. It indicates that comparing with technical improvement symbolized by total yield, much more margin lies in the socio-economic factors symbolized by net profit. Judging from the number of counties with output slacks, 14 counties can be improved in net profit, while 11 counties can increase their yields based on the results of DEA. Thus, the deepening of concerning institutional and political reforms, including the optimization of marketing regulation, integration of agro-aiding funds, etc., is important for the improvement of corn production efficiency.

In DEA models, slacks and radial movements show the redundant and inefficient amounts of inputs, respectively (Coelli et al., 2005). Meanwhile, as illustrated by Martine et al. (2003), since slacks indicate the inputs that are in excess supply, number of DMUs (here refer to the counties) shows the constraining capacity of each variable to the production efficiency, and the smaller the higher. As mentioned above, for the counties fall into Type I and II, the technical efficiencies equal to 1 and there will be no margin to adjust the input with the same level of output. Therefore, slack analysis is conducted only in the 15 counties of Type III. Table 3 shows that, machine rent is supplied with most redundant amount of 7.13 percent; farming time is the most constraining input, with only 0.26 percent in excess supplies (Fig. 1). As demonstrated in many researches including the prior study of the authors (Li et al., 2011), agricultural labor is in excess supply, and the reduction of which will improve the development of agriculture in China. The similar relative constraining capacity of the inputs can be obtained through counting the number of counties with slack in each variable, as shown in the bottom of Table 3.

The movements of radial show that amongst the 6 inputs, there is no significant difference in the ratio of radical adjustments, and each input can be saved about 6-7 percent comparing with the benchmarking counties, for each county measured as inefficient in Type III. Amongst the 6 inputs, irrigation cost is most inefficient with the largest radial amount of 7.02 percent to be reduced, while the fertilizer can be saved with the least average ratio of 6.04 percent (Fig. 2). It indicates the efficient application of fertilizer is of great importance for agriculture, as similar with the findings in prior study of the authors (Li et al., 2011).

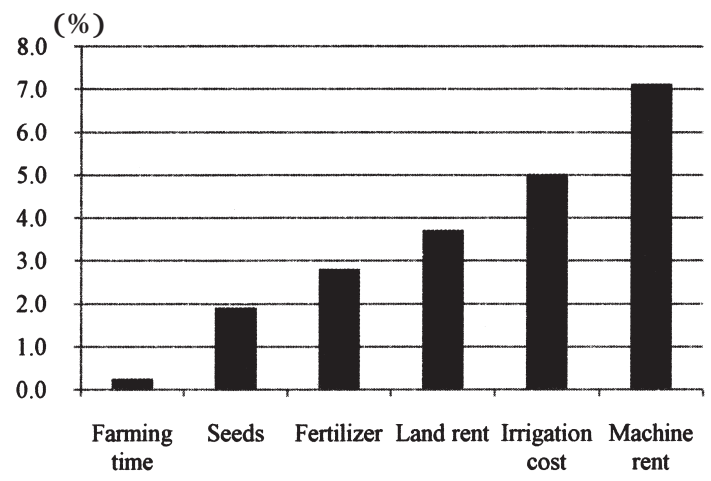

Fig. 1. Percentage of input slacks.

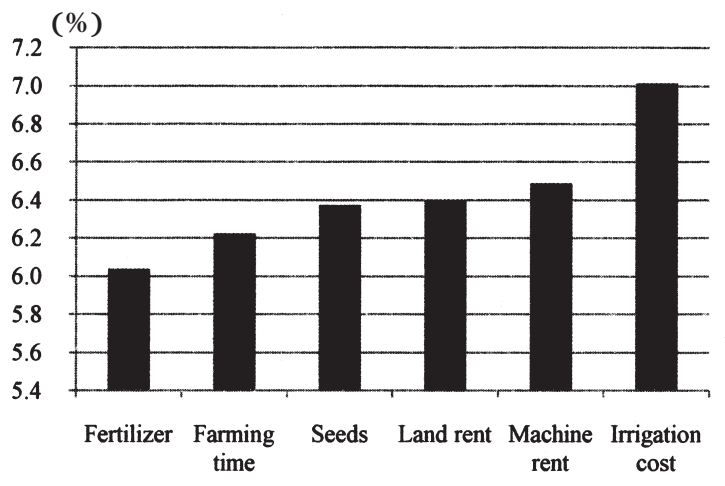

Fig. 2. Percentage of input radials.

Table 3. Slack and radial movements per $m u$ in counties of Type III

\begin{tabular}{|c|c|c|c|c|c|c|c|c|}
\hline & \multicolumn{2}{|c|}{ Output } & \multicolumn{6}{|c|}{ Input } \\
\hline & $\begin{array}{l}\text { Yield } \\
(k g)\end{array}$ & $\begin{array}{l}\text { Profit } \\
\text { (yuan) }\end{array}$ & $\begin{array}{l}\text { Farming time } \\
\qquad(d a y)\end{array}$ & $\begin{array}{l}\text { Land rent } \\
\text { (yuan) }\end{array}$ & $\begin{array}{l}\text { Seeds } \\
(k g)\end{array}$ & $\begin{array}{l}\text { Fertilizer } \\
\quad(k g)\end{array}$ & $\begin{array}{l}\text { Machine rent } \\
\text { (yuan) }\end{array}$ & $\begin{array}{l}\text { Irrigation cost } \\
\quad \text { (yuan) }\end{array}$ \\
\hline Mean of original value & 447.71 & 127.20 & 6.78 & 103.44 & 2.86 & 17.80 & 58.73 & 20.72 \\
\hline Mean of slack & 26.59 & 83.80 & -0.02 & -3.86 & -0.06 & -0.50 & -4.19 & -1.04 \\
\hline Mean of radial & 0.00 & 0.00 & -0.42 & -6.63 & -0.18 & -1.08 & -3.81 & -1.45 \\
\hline Mean of target value & 474.29 & 211.00 & 6.34 & 92.96 & 2.62 & 16.22 & 50.73 & 18.23 \\
\hline Percentage of slack (\%) & 1.93 & 15.88 & -0.26 & -3.73 & -1.92 & -2.82 & -7.13 & -5.02 \\
\hline Percentage of radial (\%) & 0.00 & 0.00 & -6.23 & -6.41 & -6.38 & -6.04 & -6.49 & -7.02 \\
\hline Number of counties with slack & 11 & 14 & 2 & 3 & 3 & 2 & 5 & 4 \\
\hline
\end{tabular}




\section{Comparison of efficient and inefficient counties}

Based on the technical efficiency scores (Tech) provided by DEA, we can compare and obtain the general traits of the output and input variables in efficient (Tech=1) and inefficient $($ Tech $<1)$ counties, thus verify the results of slack and radial analysis above and generate new findings. As shown in Table 4, both the physical and monetary outputs in the efficient counties are larger than those in the inefficient counties. Especially, the net profits differ 62.92 percent between the two kinds of counties, which is much larger than the gap of yield of main product as 7.13 percent. Fortunately, as demonstrated above, through the theoretical adjustments proposed by DEA, the monetary profit can be increased with a margin larger than that of the physical yields in the 15 technically inefficient counties.

Nevertheless, all the efficient counties used less input than the inefficient ones. The ratios in the bottom of Table 4 show the percentages of inputs in the efficient and inefficient counties, the smaller of which means the more redundant and inefficient supply of the corresponding input, and vice versa. Similar with the results in slack and radial analysis, the irrigation cost is indicated as the most redundant and inefficient input, while the smallest differences are demonstrated as existing between the fertilizer and seeds.

\section{Comparison of production efficiency between corn and wheat}

Based on the same survey by the Price and Cost Inspection Bureau of Hebei, we have measured the production efficiency of wheat (Li et al., 2010), another most important grain crop in Hebei ${ }^{5}$. The survey gathered data on both corn and wheat in 32 counties. Using DEA models in these counties can provide greater insights into the production efficiency of grain crops in this province, hence further countermeasures can be drawn as well.

Crosstabs Analysis is an interdependence technique to explore the relationships of two numeric or categorical variables, in which the entries are the frequencies of responses that fall into each cell of contingency tables in matrix formats (Joseph F. et al., 2010). Through the application of SPSS 13.0, Crosstabs Analysis identifies

Table 4. Comparison of outputs and inputs per $m u$ in efficient and inefficient counties

\begin{tabular}{|c|c|c|c|c|c|c|c|c|}
\hline & \multicolumn{2}{|c|}{ Output } & \multicolumn{6}{|c|}{ Input } \\
\hline & $\begin{array}{l}\text { Yield } \\
(k g)\end{array}$ & $\begin{array}{l}\text { Net profit } \\
\text { (yuan) }\end{array}$ & $\begin{array}{l}\text { Irrigation cost } \\
\quad(\text { yuan })\end{array}$ & $\begin{array}{l}\text { Machine rent } \\
\text { (yuan) }\end{array}$ & $\begin{array}{l}\text { Farming time } \\
\qquad(d a y)\end{array}$ & $\begin{array}{c}\text { Land rent } \\
\text { (yuan) }\end{array}$ & $\begin{array}{c}\text { Fertilizer } \\
(k g)\end{array}$ & $\begin{array}{c}\text { Seeds } \\
(k g)\end{array}$ \\
\hline (1) $\mathrm{Tech}=1$ & 479.61 & 207.23 & 17.79 & 52.47 & 6.32 & 99.28 & 17.23 & 2.80 \\
\hline (2) $\mathrm{Tech}<1$ & 447.71 & 127.20 & 20.72 & 58.73 & 6.78 & 103.44 & 17.80 & 2.86 \\
\hline$(3)=(1) /(2) \times 100 \%$ & 107.13 & 162.92 & 85.85 & 89.34 & 93.16 & 95.98 & 96.79 & 97.95 \\
\hline
\end{tabular}

Table 5. Crosstabs analysis between corn and wheat production by SPSS 13.0

\begin{tabular}{|c|c|c|c|c|c|}
\hline Model $^{\text {a }}$ & & Variables and co & s of counties ${ }^{b}$ & & Tests of 2-sided significance \\
\hline \multirow{4}{*}{$\mathrm{Tc} \times \mathrm{Tw}$} & & Inefficient Tw & Efficient Tw & Total & \\
\hline & Inefficient Tc & $7(4.5)$ & $2(4.5)$ & 9 & Pearson $\chi^{2}(1)=3.865$ \\
\hline & Efficient Tc & $9(11.5)$ & $14(11.5)$ & 23 & Asymp. Sig. of Pearson $\chi^{2}=0.049$ \\
\hline & Total & 16 & 16 & 32 & Sig. of Fisher's exact test=0.113 \\
\hline \multirow{4}{*}{$\mathrm{Sc} \times \mathrm{Sw}^{* *}$} & & $\operatorname{crs} \mathrm{Sw}$ & irs Sw & Total & \\
\hline & crs Sc & $9(5.6)$ & $9(12.4)$ & 18 & Pearson $\chi^{2}(1)=6.732$ \\
\hline & $\operatorname{irs~Sc}$ & $1(4.4)$ & $13(9.6)$ & 14 & Asymp. Sig. of Pearson $\chi^{2}=0.009$ \\
\hline & Total & 10 & 22 & 32 & Sig of Fisher's exact test=0.019 \\
\hline \multirow{4}{*}{$\mathrm{Tc} \times \mathrm{Sc}^{* * *}$} & & $\operatorname{crs~Sc}$ & irs Sc & Total & \\
\hline & Inefficient Tc & $0(5.1)$ & $9(3.9)$ & 9 & Pearson $\chi^{2}(1)=16.099$ \\
\hline & Efficient Tc & $18(12.9)$ & $5(10.1)$ & 23 & Asymp. Sig. of Pearson $\chi^{2}=0.000$ \\
\hline & Total & 18 & 14 & 32 & Sig of Fisher's exact test $=0.000$ \\
\hline \multirow{4}{*}{$\mathrm{Tw}_{\mathrm{W}} \times \mathrm{Sw}^{* * *}$} & & $\operatorname{crs} \mathrm{Sw}$ & irs Sw & Total & \\
\hline & Inefficient Tw & $0(5.0)$ & $16(11.0)$ & 16 & Pearson $\chi^{2}(1)=14.545$ \\
\hline & Efficient Tw & $10(5.0)$ & $6(11.0)$ & 16 & Asymp. Sig. of Pearson $\chi^{2}=0.000$ \\
\hline & Total & 10 & 22 & 32 & Sig of Fisher's exact test $=0.000$ \\
\hline
\end{tabular}

Note: ${ }^{a}$ Tc and Tw represent the technical efficiency of corn and wheat, while Sc and Sw means the status of returns to scale of corn and wheat, respectively; ***, **and * denote statistical significance in the level of 1\%, 5\% and 10\% by Fisher's exact test, respectively. ${ }^{\mathrm{b}}$ numerals in the ( ) are the expected counts.

5 In 2008, the sown areas and aggregate yields of wheat in Hebei accounts for 10.23 and 10.87 percent in China, and both of the two indices ranked the $3^{\text {rd }}$ in 31 provincial regions. 
the relationships between technical efficiency and status of returns to scale in corn and wheat production as shown in Table 5.

In Crosstabs analysis, the Chi-square test assumes that the expected value for each cell is 5 or higher, but the Fisher's exact test has no such assumption and can be used regardless of how small the expected frequency is (Bruin, 2006). As except for the last model, the assumption of Chi-square test cannot be met in this study, the Fisher's exact tests are used to measure the relationships of different type of counties.

According to the Fisher's exact tests, statistically significant relationship does not exist between Tc and Tw, while it does exist between Sc and Sw. The insignificant relationships between technical efficiency of corn and wheat may be resulted from the fact that, wheat is the most important food crop in Hebei, while corn is serving as forage crop in most of the cases. Affected by the traditional concepts like the more fertilizer, the higher yields, irrational and blind over-fertilization are quite common amongst Chinese farmers (Zhang et al., 2007), thus the wheat is inputted more than that of the corn $^{6}$. At the same time, because corn and wheat are usually multiple cropped on the same plot of land in Hebei Province (Han, 2006), the significant relationships of status on returns to scales with the two crops appeared in the 32 counties. Meanwhile, due to the laws of crop growth and yields within either of the two crops, significant relationships are demonstrated between technical efficiency and status of returns to scale. Farming scales should be increased in all the 9 inefficient counties of corn and the 16 inefficient counties of wheat production. In the efficient counties of both corn and wheat production, most of them are in the status of constant returns to scale.

In addition, judging from the counts of counties and the average scores of technical and scale efficiency of each county ${ }^{7}$, we can conclude that in the 32 counties, corn is more efficient than wheat production; as the main way to improve production efficiency, increasing the farming scales is more important to the wheat.

\section{CONCLUSIONS AND RECOMMENDATIONS}

\section{Main conclusions}

Through the adoption of DEA models, this study measures the efficiency of corn production in 44 counties of Hebei Province, China. According to the efficiency scores provided by DEA, the 44 sampled counties are divided into 3 types. In Type I, the 22 counties are fully efficient and in the status of constant returns to scale, thus forming benchmarks for the other inefficient counties. In the 7 counties of Type II, due to the technical scores fixed to one, adjustment of any input will not change the output efficiency, thus production efficiency can only be improved through expanding the managerial scales in 5 counties, while the other 2 counties should compress their scales. Meanwhile, in the rest 15 counties of Type III, production efficiency can be improved through either reducing some of the inputs or compressing the managerial scales.

The output slacks analysis shows that, comparing with physical yields, net profit can be increased with a larger average margin. The similar conclusions are drawn from the comparison of outputs in the efficient and inefficient counties. It indicates that comparing with technical improvement symbolized by total yield, much more margin lies in the socio-economic factors symbolized by net profit. In general, the liquid inputs including seeds, fertilizer and farming time are similar in the efficient and inefficient counties, with less slack and radial movements. Meanwhile, larger differences, slack and radial movements exist amongst inputs connecting with the construction of agricultural infrastructure, including the irrigation costs and machinery rents.

The crosstabs analysis of production efficiency between corn and wheat in 32 counties indicates that, statistically significant relationship does not exist between Technical efficiency, while it does exist between the returns to scale cross the two crops. However, significant relationship between the two types of variables within either of corn and wheat. Further comparison shows that corn is more efficient than wheat production; as the main way to improve production efficiency, increasing the farming scales is more important for wheat production.

\section{Policy recommendations}

According to the analysis above, corn production is more efficient than wheat in the sampled counties of Hebei Province. Therefore, steadily accelerating the corn production is of great significance to agriculture and concerning industries of Hebei Province. Because in most of the counties, enlarging the managerial scales will improve the relative production efficiency, a variety of policies should be strengthened to accelerate the enlargement of corn production. In the first place, circulation of farmland should be further encouraged, as larger farm scale can generate more penitential for efficient farming modes. In China, land performs as self insurance of subsistence for a long period. The government should encourage the concentration of land on farms' own willing, through favorite subsidies, financial and technological aids (Meng J. et al., 2010). Moreover, since the farmers cooperatives are developing quickly in latest year, especially after the execution of the Law on Specialized Farmers' Cooperatives in 2007, the cooperatives should be guided and encouraged to support corn production, including the purchase of capital goods, product marketing, credit accessing, etc. In some

\footnotetext{
${ }^{6}$ In this survey of the 32 counties, the average inputs of fertilizer, mechanical rent and irrigation per mu of corn were $17.12 \mathrm{~kg}, 57.01$ yuan and 19.98 yuan, while the corresponding inputs on wheat were $28.22 \mathrm{~kg}, 91.87$ yuan and 45.36 yuan, respectively.

According to the results of DEA, the average scores of technical and scale efficiency with corn are 0.981 and 0.958 , while the corresponding scores with wheat are 0.949 and 0.936 , respectively.
} 
regions, Corn Farmers' Cooperatives can be founded through the support of government.

Facilitating the marketing of corn products, thus improve the value added and net profits of corn production. As reviewed by Gu L. (2010), the accelerated development of food processing and livestock industries is vital to corn production. The direct associations between corn farmers and enterprises should be reinforced, thus shortening the marketing chain and corresponding costs. Moreover, the byproducts of corn, including the straw, cob, etc, should be exploited through the development of relevant industries (Yang Q., 2008).

Accelerating the construction of irrigating infrastructure and the process of agricultural mechanization, hence decrease the cost of irrigation and machinery operations. In the first place, as described in the No. 1 Document of the Central committee of $\mathrm{CCP}^{8}$, take full advantages from the special funds for the construction of water resources, accelerating the renovation of irrigating facilities and extension of water-saving facilities. Meanwhile, extend the efficient application of machine for the corn production, especially for harvest, through subsidizing the purchasers and research agencies. The financial institutions should be encouraged to support the corn machinery buyers, with lower interest rates, simpler loaning conditions and procedures, etc.

\section{REFERENCES}

Aigner D., Lovell C. A. Knox and S. Peter 1977 Formulation and estimation of stochastic frontier production function models, Journal of Econometrics 6: pp. 21-37

Banker R. D., Charnes A. and Cooper W. 1984 Some models for estimating technical and scale inefficiencies in DEA, Management Science, 30, No. 9: pp. 1078-1092

Bhima D., Y. Sugimoto and N. Yamamoto 2010 Technical efficiency analysis of vegetable farms in the mid-hill region of Nepal: an approach using data envelopment analysis, Japanese Journal of Food, Agricultural and Resource Economics, 60, No. 2: pp. 27-38

Bruin J. 2006 New test: Command To Compute New Test. UCLA: Academic Technology Services, Statistical Consulting Group. http://www.ats.ucla.edu/stat/stata/ado/analysis/

Charnes A., Cooper W. and Rhodes E. 1978 Measuring the efficiency of decision making units, European Journal of Operational Research, 2: pp. 429-444

Coelli T. J., Prasada Rao D. S., O. J. Christopher and B. E. George 2005 An Introduction to Efficiency and Productivity Analysis (2nd edition), Springer Press, New York: pp. 161-181

Daniel C. M., Z. Chen and Y. Bonapartea 2010 Explaining production inefficiency in China's agriculture using data envelopment analysis and semi-parametric bootstrapping, China Economic Review, 21, Issue 2: pp. 346-354

Farrell M. J. 1957 The measurement of productive efficiency, Journal of the Royal Statistical Society, 120: pp. 253-290

$\mathrm{Gu}$ L. 2010 Overview of corn economic research in china, Chinese Journal of Corn Sciences, 18, No. 3: pp. 160-164

Han M. 2006 Planting system and geographical difference of corn in China during the past 300 years, Chinese Journal of Geographical Research, 25, No. 6: pp. 1083-1095

Herman J. B. 2004 Introduction to the Mathematical and Statistical Foundations of Econometrics, Cambridge Univ. Press, Cambridge (England) p. 211

Hu J., Wang S., and Yeh F. 2006 Total-factor water efficiency of regions in China, Resources Policy, 31: pp. 217-230

Joseph F. H., William C. B., Barry J. B. and Rolph E. A. 2010 Multivariate Data Analysis, Seventh Edition, Prentice Hall Press, USA: p. 544

Li D., T. Nanseki and K. Hotta 2010 Measurement of wheat production efficiency and the determinants in different counties of Hebei Province, China: A Model Based on Twostage DEA, Proceeding of Japanese Society of Farm Management, Akita, pp. 198-199

Li D., T. Nanseki, K. Hotta and S. Shinkai 2011 A factor analysis of Chinese agricultural development using production function: the inputs change and technological progress, 19832006, Japanese Journal of Food, Agricultural and Resources Economics, 61, No. 2: pp. 1-10

Luis D., A. C. Herruzo, Margarita M. and Jacinto G. 2006 An analysis of productive efficiency and innovation activity using DEA: an application to Spain's wood-based industry, Forest Policy and Economics, 8: pp. 762-773

Maria P., I. E. Tsolas and Dimitris M. 2010 Evaluation of credit risk based on firm performance, European Journal of Operational Research 201: pp. 873-881

Martine A., Jacky M. and Marie C. H. 2003 Social and health determinants of the efficiency of cotton farmers in Northern Côte d'Ivoire, Social Science \& Medicine, 56: pp. 1705-1717

Meng J., Han J., Yang L. and Gu Z. 2010 Analysis on the regional comparative advantages of maize production in Hebei Province, Chinese Journal of Agricultural Science Bulletin, 26 (15): pp. 343-348

Meng L. and Zhang H. 2004 Regional technical efficiency differences in corn production in China, Chinese Journal of Nanjing Agricultural University (Social Science Edition), 4, No. 2: pp. $13-16$

Wade D. Cook and Kamel B. 2007 Performance measurement and classification data in DEA: Input-oriented model, Omega, 35: pp. 39-52

Yang Q. 2008 On the corn industry strategy of economic development, Chinese Journal of Issues in Agricultural Economy, 22, No. 7: pp. 4-9

Zhang F., Cui Z., Wang J., Li C. and Chen X. 2007 Current status of soil and plant nutrient management in China and improvement strategies, Chinese Bulletin of Botany, 24 (6): pp. 687-694

Zhuo C., Wallace E. H. and Scott R. 2009 Farm technology and technical efficiency: evidence from four regions in China. China Economic Review, 20: pp. 153-161

\footnotetext{
8 As one of the most important documents from the central committee of CCP, the No. 1 document of 2011 was issued on Jan. $29^{\text {th }}$, outlined the perspectives and policies on the management of water resources. In the document, financial source was provided as in addition to the regular sources to be doubled within the next 10 years, 10 percent of revenue from land transactions will be reserved and used exclusively for the construction of water facilities.
} 